\title{
Características do bom professor segundo a percepção de estudantes de Psicologia
}

\author{
Luiza Helena Albertini Padula Trombeta ${ }^{1}$ \\ Pontifícia Universidade Católica de Campinas
}

\begin{abstract}
O objetivo do presente estudo foi verificar a opinião de estudantes de um curso de Psicologia sobre as características consideradas importantes de um bom professor. Os sujeitos foram 79 alunos, cursando a $3^{\mathrm{a}}$ série, de ambos os sexos, que foram solicitados a citar-lhe três características. Os resultados indicam que a maioria deles valoriza mais as características de personalidade e do relacionamento entre professor e aluno, do que as ligadas ao aspecto profissional propriamente dito, como conhecimentos gerais e específicos, por exemplo. As características mais citadas promovem a imagem de um professor interessado, preocupado com os alunos, simpático, bem-humorado, dinâmico e flexível.

Palavras-chave: opiniões, conceito de "bom professor", personalidade, relacionamento, interação professor-aluno.
\end{abstract}

\begin{abstract}
Characteristics of the "good" teacher according to the perception of Psychology Students The objective of this study is to investigate the oppinions of psychology students in terms of what are considered to be the important characteristics of a good teacher. The subjects consisted of 79 third year psychology students, of both sexes, who were asked to cite three characteristics. The results indicate that the majority of the subjects attribute greater value to the characteristics of personality and the teacher-student relationship, than to actual professional characteristics such as, for example, the level of specific and general knowledge. The most commonly cited characteristics support the image of an interest teacher, concerned with the student, likable, good natured, dynamic and flexible.

Key words: opinion, concept of "good teacher", personality, relationship, teacher-student interaction.
\end{abstract}

\section{Introdução}

Muito tem sido discutido sobre a influência inquestionável que as relações interpessoais que ocorrem em sala de aula e na escola como um todo exercem sobre o processo ensinoaprendizagem. As interações que acontecem na escola envolvem atitudes, crenças, valores, representações sociais das pessoas envolvidas, influências da sociedade e da cultura no ambiente extra-escolar e muitos outros fatores.

$\mathrm{O}$ interesse por estudos sobre interação professor-aluno não é novo, como pode se ob-

1. Doutoranda em Psicologia Escolar do Departamento de Pós-Graduação em Psicologia, Pontifícia Universidade Católica de Campinas, bolsista CNPq.

Endereço para correspondência: Rua Gil Vicente, 88, Parque Taquaral, CEP 13087-030, Campinas, SP. servar examinando a literatura nas áreas da Educação, da Psicologia e de outras ciências afins.

Gil (1992) bem lembra que os problemas educacionais não começam e nem terminam na escola, e que a relevância social da pesquisa da interação professor/aluno está na relação entre ensino-aprendizagem escolar e na construção do conhecimento pelo aluno.

Diversas pesquisas concluem que o comportamento do professor em sala de aula interfere e muito no comportamento e na aprendizagem do aluno. Duran (1987) ressalta a importância em se considerar a interação professor-aluno pela ótica bidirecional, atentando para a atuação das duas partes envolvidas, o professor e o aluno, já que existe um intercâmbio de influências comportamentais. 
Del Prette (1994) enfatiza a possibilidade de o professor ser capaz de implementar interações significativas entre o aluno e o objeto de conhecimento, ou seja, interações que efetivamente promovam o desenvolvimento e a aprendizagem. O autor coloca ainda que tais interações incluem a participação mais direta do professor além das atividades em que a participação é mais indireta, de suporte e mediação.

Khouri (1984) relata pesquisa com adolescentes de escola pública em que as propostas dos alunos em relação aos professores centramse mais nos processos afetivos, no vínculo professor-aluno, do que em processos intelectuais do professor. O aspecto da interação em si e do vínculo afetivo parecem de fato ser importantes na caracterização do bom professor.

Machado (1987) faz uma revisão de diversas pesquisas apontando variáveis que interferem na interação professor-aluno, relacionadas ao professor, aos alunos e à situação. Os aspectos analisados mostram que, sem dúvida, a interação que ocorre em sala de aula é um fator importante na aprendizagem dos alunos. Os vários aspectos envolvidos devem, portanto, ser considerados, ou seja, as características do professor, dos alunos e do contexto.

O presente estudo focalizou a opinião de alunos a respeito de características importantes do bom professor, com o objetivo de conhecer melhor a realidade específica desta amostra, considerando que cada contexto educacional é único e faltam dados descritivos de realidades diversas.

\section{Método}

\section{Sujeitos}

A amostra foi composta de 79 alunos (67 do sexo feminino e 12 do sexo masculino) da $3^{\text {a }}$ série do curso de Psicologia de uma instituição privada de ensino superior, cujas idades variavam entre 20 e 40 anos (idade média igual a 30 anos).

\section{Procedimento}

Durante uma aula, os alunos foram solicitados a escrever as três características que julgassem mais importantes para que o professor fosse considerado bom. A tarefa foi realizada individualmente.

\section{Resultados e Discussão}

Os resultados obtidos pelas respostas dos estudantes foram analisados e classificados em três grandes categorias; uma, referente às características pessoais e de personalidade do professor; a segunda — relação interpessoal — diz respeito à interação professor e aluno na sala de aula, e a última categoria refere-se aos aspectos da atividade profissional do professor, ou seja, aqueles demonstrados pelo professor em sala de aula no exercício da atividade docente, como por exemplo, conhecimentos gerais e da disciplina, formação e atualização.

Os resultados encontrados mostram uma valorização das características de personalidade e aquelas relacionadas à interação positiva e próxima entre professor e aluno.

A Tabela I mostra como as respostas foram distribuídas por categoria. De um total de 237 respostas, encontramos $62,5 \%$ nas categorias I e II, que referem-se aos aspectos mais valorizados (características de personalidade e da relação professor /aluno).

A valorização destes aspectos na maioria das respostas reflete a preocupação com uma educação mais humanista. 
Tabela 1. Distribuição das respostas por categoria

\begin{tabular}{|c|c|c|}
\hline Categorias & R & \% \\
\hline I & 109 & 46,0 \\
\hline II & 39 & 16,5 \\
\hline III & 89 & 37,5 \\
\hline Total & $\mathbf{2 3 7}$ & $\mathbf{1 0 0}$ \\
\hline
\end{tabular}

De acordo com cada categoria as respostas aparecem distribuídas em subcategorias mais específicas, apontando elementos que podem detalhar as características que os alunos valorizam nos seus professores.

A Tabela 2 mostra a distribuição das respostas nas categorias: I - Características pessoais e de personalidade do professor e II - Características relacionadas à relação professor-aluno.

As características de personalidade que aparecem como mais importantes para o bom professor, na opinião dos alunos pesquisados, são: simpatia e bom humor, flexibilidade, dinamismo e interesse / motivação pelo trabalho, todas com 11 a $12 \%$ das respostas obtidas.

No mesmo nível de importância, com 13,5\% das respostas, está o respeito e a compreensão pelo aluno, que dizem respeito à categoria II.

Outras características também lembradas podem ser observadas na Tabela 2 .

Na Tabela 2 podem ser vistos os resultados obtidos quanto à categoria III: Características profissionais do professor, que também foram bastante citadas, $37,5 \%$ do total de respostas (vide Tabela I).
Tabela 2. Características relacionadas à personalidade do professor e à relação professor/aluno

\begin{tabular}{|l|c|c|}
\hline $\begin{array}{c}\text { Características de personalidade e } \\
\text { de relação interpessoal }\end{array}$ & Respostas & $\%$ \\
\hline simpatia/bom humor & 19 & 12,83 \\
\hline dinamismo & 17 & 11,48 \\
\hline flexibilidade & 17 & 11,48 \\
\hline interesse/motivação & 17 & 11,48 \\
\hline paciência & 12 & 8,10 \\
\hline criatividade & 6 & 4,05 \\
\hline coerência & 6 & 4,05 \\
\hline liderança & 6 & 4,05 \\
\hline simplicidade/humildade & 5 & 3,37 \\
\hline segurança & 4 & 2,70 \\
\hline respeito e compreensão pelo aluno & 20 & 13,51 \\
\hline proximidade/interação positiva & 14 & 9,45 \\
\hline $\begin{array}{l}\text { adequação à realidade e à necessi- } \\
\text { dade do aluno }\end{array}$ & 5 & 3,37 \\
\hline & 148 & 100 \\
\hline
\end{tabular}

A característica mais valorizada foi a boa didática, com $58,4 \%$ das respostas desta categoria, seguida do conhecimento específico da disciplina com a qual o professor trabalha, 17,9\%. Os dados encontram-se na Tabela III.

Outros aspectos também considerados importantes e lembrados pelos alunos foram: conhecimentos gerais, avaliação constante, formação acadêmica, pontualidade e experiência. 
Tabela 3. Características relacionadas à competência profissional do professor

\begin{tabular}{|l|c|c|}
\hline $\begin{array}{l}\text { Características relacionadas a aspec- } \\
\text { tos profissionais da atividade docente }\end{array}$ & Respostas & $\%$ \\
\hline boa didática & 52 & 58,4 \\
\hline $\begin{array}{l}\text { conhecimento específico da disci- } \\
\text { plina ministrada }\end{array}$ & 16 & 17,9 \\
\hline conhecimentos gerais & 8 & 8,98 \\
\hline avaliação constante & 5 & 5,61 \\
\hline formação acadêmica / atualização & 4 & 4,49 \\
\hline pontualidade & 2 & 2,24 \\
\hline experiência & 2 & 2,24 \\
\hline TOTAL & 89 & 100 \\
\hline
\end{tabular}

\section{Conclusões}

Os aspectos mais citados pelos alunos referem-se às características pessoais do professor e aos aspectos do relacionamento humano e da interação social entre professor e aluno.

A valorização pelos alunos pesquisados dos aspectos citados demonstra que a competência profissional do professor também é considerada importante, porém, não exclusiva e prioritariamente.

O importante parece ser o professor estar próximo, interessado e preocupado com o aluno, não só com seu rendimento escolar, mas com o aluno como pessoa. O professor aberto, amigo, que permite que o aluno também o veja como pessoa favorece a criação de um ambiente mais propício à aprendizagem em sala de aula.

A interação professor-aluno, o vínculo entre eles e o abandono das idéias de que o professor sabe mais que o aluno, de que pode e deve julgá-lo e ainda determinar seus interesses, demonstram a percepção dos próprios alunos sobre a necessidade de uma educação mais humanista, preocupada com a formação de seres humanos e não somente com sua informação. Aspecto este que vem sendo bastante discutido por pesquisadores e técnicos relacionados à área, assim como veiculado pela mídia em geral.

O reconhecimento da importância da interação professor-aluno para uma educação efetiva já é um grande passo em direção às mudanças necessárias, desde a formação préescolar e de $1^{\circ}$ grau, passando pelo magistério até os bancos das Universidades.

\section{Referências}

Del Prette, A. e Del Prette Z. (1994). Interações sociais em sala de aula: representações do professor. Anais do XVII International School Psychology Colloquium e II Congresso Nacional de Psicologia Escolar, pp. 426 - 430.

Duran, A. P. (1992). O enfoque da interação social: contribuições à escola. Anais do I Congresso $\mathrm{Na}$ cional de Psicologia Escolar, pp. 115 - 117.

Gil, M.S.C. de A. (1992). Interação professor-aluno:um processo e seus produtos. Anais do I Congresso Nacional de Psicologia Escolar, pp. 122 124.

Khouri, Y.G. e col. (1984). Psicologia Escolar, EPU, 1.

Machado, V.L.S. (1987). Aprendizagem e interação professor - aluno. In: G.P. Witter e J.F.B. Lomônaco. Psicologia da aprendizagem/aplicações na escola, EPU, 9(3):15-35. 